DOI: 10.2478/romneu-2014-0001

\title{
Microsurgical management of deep ruptured arteriovenous malformations of the basal ganglia and thalamus
}

\author{
Aurelia Mihaela Sandu ${ }^{1}$, Andrei Giovani ${ }^{1}$, Catioara Fănica Cristescu ${ }^{2}$, \\ Mircea Radu Gorgan ${ }^{3}$ \\ ${ }^{1} \mathrm{PhD}$ Student in Neurosurgery, University of Medicine and Pharmacy "Carol Davila" \\ Bucharest, Faculty of Medicine, Department of Neurosurgery, Clinic of Neurosurgery, \\ Fourth Department of Neurosurgery, Emergency Clinical Hospital Bagdasar-Arseni, \\ Bucharest \\ ${ }^{2}$ Department of Anesthesiology and Intensive Care, Emergency Clinical Hospital Bagdasar- \\ Arseni, Bucharest \\ ${ }^{3}$ Professor in Neurosurgery, University of Medicine and Pharmacy "Carol Davila" Bucharest, \\ Faculty of Medicine, Department of Neurosurgery, Head of the Clinic of Neurosurgery, \\ Emergency Clinical Hospital Bagdasar-Arseni, Bucharest
}

\begin{abstract}
Introduction: Deep AVMs are more difficult to operate compared with other supratentorial locations due to the long working corridor through the brain, location in eloquent areas and vicinity with brain critical structures.
\end{abstract}

Material and Method: We report a series of 7 cases with deep AVMs operated in the Fourth Department of Neurosurgery, Emergency Clinical Hospital Bagdasar-Arseni, between 2009 and 2013.

Results: Six patients had ruptured AVMs and one presented frequent, refractory seizures due to a deep large porencephalic cyst. At admission, one patient presented mRS 2, 3 patients had mRS 4 and 3 patients had mRS 5. Patients underwent surgery and we achieved total resection in 5 patients and we left a residual nidus in two cases. These last 2 patients with residual nidus were referred to stereotactic radiosurgery Gamma Knife with good results. Following surgery mRS improved in all 7 patients, 3 had mRS 1, 3 had mRS 3 and one mRS 4. Outcome was favorable in 3 cases and slowly favorable in 4 patients.

Conclusions: Deep AVMs frequently present sudden onset, with altered mental state, motor deficits and large intraparenchymatal hematomas. Surgery is mandatory for deep ruptured AVMs, being the only treatment that can provide neurological improvement through hematoma evacuation and cure through nidus resection. In experienced hands, deep AVMs can be successfully resected. Postoperative results are good, with improvement of state of consciousness and motor deficits. Adequate patient selection 
is essential in order to achieve a good postoperative outcome.

Key words: deep arteriovenous malformation, AVM surgery, transsylvian approach.

\section{Introduction}

Treatment of deep seated arteriovenous malformations (AVMs), located into basal ganglia and thalamus, continues to be in debate between those who favor microsurgery (23) and those who favor embolization or stereotactic radiosurgery (27). Even though many neurosurgeons incline towards nonsurgical treatment for these very complex vascular lesions, involving embolization and stereotactic radiosurgery, none of those methods proved to be complications free. $(1 ; 2 ; 11$; 13; 19-21) In fact, in experienced hands, microsurgery proved to have better results, compare to other treatments. $(8 ; 22 ; 23)$

Natural history showed that deep AVMs are prone to have a higher bleeding rate compare to AVMs with different locations, bleeding rate being as high as 9.8-34.4\%/year (4; 29) and many times these patients are admitted with ruptured AVMs.

Smaller AVMs, grade I and II SpetzlerMartin are usually considered for surgical resection whether in grade III, some neurosurgeons favor radiosurgery. Grade IV and V AVMs, if unruptured, should benefit of follow-up, but once ruptured when they present with intraparenchymatal hemorrhage surgery should be attempted. After a successfully microsurgical treatment the lesion is considered cured, whereas an AVM treated only by embolization, which is used mostly as adjuvant and/or radiosurgery cannot be considered completely cured. (9)

These deep seated AVMs are considered to be more complex than other supratentorial AVMs, given the corridor that the surgeon has to create into the brain parenchyma in order to approach them and also because they are close to the thalamus and internal capsule. These are very aggressive lesions with annual hemorrhage rates as high as $34 \%$ and mortality rates of $62.5 \%$ after rupture. (4; 29) Compared to natural history that deem this lesions as inoperable for most of the neurosurgeons, literature data show that when attempted surgery results were very good, with a $91 \%$ complete resection rate and low postoperative mortality of $2.4 \%$. $(14 ; 23)$

\section{Material and method}

We report a series of 7 cases with deep AVMs operated in the Fourth Department of Neurosurgery, Emergency Clinical Hospital Bagdasar-Arseni, between November 2009 and June 2013, by a single neurosurgeon (M.R.G.). Medical records were retrospectively reviewed. Patients that were not operated were excluded. We recorded and analyzed: demographic data, history, signs and symptoms at admission, general exam, neurological exam, cerebral CT scan, MRI, angio-CT, four vessel angiography and fundoscopy, details regarding surgery, outcome, complications, 
other treatments needed, and prognosis. Follow-up period varied between 6 months and 4 years. At follow-up patients were evaluated using all or some of the followings: general exam, neurological exam, cerebral CT, four vessels angiography and fundoscopy.

\section{Results}

Results are shown in Table I.

Age varied from 25 to 40 years old. All 7 patients were women.
Six (6/7) patients presented sudden onset, with altered mental state and new onset neurological deficits. All 6 patients had ruptured AVMs with intraparenchymatal hematoma and intraventricular bleeding.

Only one patient presented long medical history, with frequent, refractory seizures and mild left brachial paresis; onset of seizure was at age 14; seizures were refractory to high dose, complex antiepileptic drugs.

TABLE I

\begin{tabular}{|c|c|c|c|c|c|c|c|c|}
\hline No & $\begin{array}{l}\text { Sex, } \\
\text { age } \\
\text { (y.o.) }\end{array}$ & Grade SM & $\begin{array}{l}\text { Hem } \\
\text { rrhag }\end{array}$ & Neurological exam & $\overline{G C S}$ & $m R S$ & Feeding arteries & Draining veins \\
\hline 1 & $\overline{\mathrm{F}, 25}$ & $\begin{array}{l}\text { III } \\
(\mathrm{S} 2 \mathrm{E} 1 \mathrm{~V} 0)\end{array}$ & Yes & $\begin{array}{l}\text { right hemiparesis } \\
\text { altered mental state, } \\
\text { coma }\end{array}$ & 6 & 5 & $\begin{array}{l}\text { talamostriate arteries from } \\
\text { PCoA and PCA, AChA, } \\
\text { perforating branches from } \\
\text { M1 }\end{array}$ & $\begin{array}{l}\text { transverse } \\
\text { sinus }\end{array}$ \\
\hline 2 & F, 27 & $\begin{array}{l}\text { IV } \\
(\mathrm{S} 2 \mathrm{E} 1 \mathrm{~V} 1)\end{array}$ & Yes & $\begin{array}{l}\text { right hemiplegia, } \\
\text { aphasia, altered } \\
\text { mental state }\end{array}$ & 13 & 4 & $\begin{array}{l}\text { lenticulostriate arteries } \\
\text { from M1, branches from } \\
\text { M2, AChA }\end{array}$ & $\begin{array}{l}\text { internal } \\
\text { cerebral vein }\end{array}$ \\
\hline 3 & F, 28 & $\begin{array}{l}\text { III } \\
(\mathrm{S} 1 \mathrm{E} 1 \mathrm{~V} 1)\end{array}$ & Yes & $\begin{array}{l}\text { left hemiplegia, } \\
\text { altered mental state }\end{array}$ & 13 & 4 & $\begin{array}{l}\text { thalamoperforating arteries } \\
\text { from P1 and PCoA, } \\
\text { posterior medial choroidal } \\
\text { artery }\end{array}$ & $\begin{array}{l}\text { internal } \\
\text { cerebral vein }\end{array}$ \\
\hline 4 & F, 35 & $\begin{array}{l}\text { III } \\
\text { (S1 E1V1) }\end{array}$ & Yes & $\begin{array}{l}\text { right hemiplegia, } \\
\text { altered mental state, } \\
\text { coma }\end{array}$ & 6 & 5 & $\begin{array}{l}\text { lenticulostriate arteries } \\
\text { from M1, branches from } \\
\text { M2 }\end{array}$ & $\begin{array}{l}\text { internal } \\
\text { cerebral vein }\end{array}$ \\
\hline 5 & F, 27 & $\begin{array}{l}\text { IV } \\
(\mathrm{S} 2 \mathrm{E} 1 \mathrm{~V} 1)\end{array}$ & Yes & $\begin{array}{l}\text { right hemiparesis, } \\
\text { altered mental state }\end{array}$ & 9 & 4 & $\begin{array}{l}\text { lenticulostriate arteries } \\
\text { from M1, branches form } \\
\text { M2, thalamoperforating } \\
\text { arteries from P1, PChA }\end{array}$ & $\begin{array}{l}\text { internal } \\
\text { cerebral vein }\end{array}$ \\
\hline 6 & $\overline{F, 29}$ & $\begin{array}{l}\text { III } \\
\text { (S2E1V0) }\end{array}$ & No & $\begin{array}{l}\text { frequent, refractory } \\
\text { seizures, mild left } \\
\text { brachial paresis }\end{array}$ & 15 & 2 & $\begin{array}{l}\text { lenticulostriate arteries } \\
\text { from M1, branches form } \\
\text { M2, thalamoperforating } \\
\text { arteries from PCoA }\end{array}$ & $\begin{array}{l}\text { superior } \\
\text { sagittal sinus }\end{array}$ \\
\hline 7 & $\overline{F, 40}$ & $\begin{array}{l}\text { III } \\
(\mathrm{S} 1 \mathrm{E} 1 \mathrm{~V} 1)\end{array}$ & Yes & $\begin{array}{l}\text { left hemiplegia } \\
\text { severe altered } \\
\text { mental state, coma }\end{array}$ & 4 & 5 & AChA, branches from M2 & straight sinus \\
\hline
\end{tabular}


TABLE I (continuation)

\begin{tabular}{|c|c|c|c|c|c|c|}
\hline No & Approach & $\begin{array}{l}\text { Posto } \\
\text { P } \\
m R S\end{array}$ & $\begin{array}{l}\text { Complete } \\
\text { resection/residual } \\
\text { nidus }\end{array}$ & Outcome & $\begin{array}{l}\text { Residual } \\
\text { neurological deficits }\end{array}$ & Observations \\
\hline 1 & transsylvian & 1 & residual nidus & favorable & none & $\begin{array}{l}\text { SRS Gamma Knife on } \\
\text { the residual nidus }\end{array}$ \\
\hline 2 & transcortical & 3 & complete resection & $\begin{array}{l}\text { slowly } \\
\text { favorable }\end{array}$ & $\begin{array}{l}\text { right hemiparesis, } \\
\text { dysphasia }\end{array}$ & \\
\hline 3 & transsylvian & 3 & residual nidus & favorable & left hemiparesis & $\begin{array}{l}\text { SRS Gamma Knife on } \\
\text { the residual nidus }\end{array}$ \\
\hline 4 & transsylvian & 3 & complete resection & $\begin{array}{l}\text { slowly } \\
\text { favorable }\end{array}$ & $\begin{array}{l}\text { right hemiparesis, } \\
\text { dysphasia }\end{array}$ & \\
\hline 5 & transcortical & 1 & complete resection & favorable & none & \\
\hline 6 & transsylvian & 1 & complete resection & favorable & $\begin{array}{l}\text { none; seizure-free } \\
\text { under reduced doses } \\
\text { of antiepileptic } \\
\text { drugs }\end{array}$ & $\begin{array}{l}\text { Preop imaging: large } \\
\text { porencephalic cyst }\end{array}$ \\
\hline 7 & transsylvian & 4 & complete resection & $\begin{array}{l}\text { slowly } \\
\text { favorable }\end{array}$ & left hemiparesis & \\
\hline
\end{tabular}

Preoperative imaging (CT and MRI) showed a deep large porencephalic cyst, as a sign of a previous bleeding. Medical history revealed an episode of a possible rupture of the AVM at age 14, which is not medical documented.

All 6 patients with ruptured AVMs (6/7) were admitted with altered mental state and 3 presented comatose state. At admission, only one patient presented slight disability (mRS 2), 3 patients had moderately severe disability ( $\mathrm{mRS} 4$ ) and all 3 comatose patients had severe disability (mRS 5).

All patients with deep AVMs had some degree of motor deficit, 4 had paralysis of right side and 3 on the left side of the body.

Feeding arteries originated from MCA, M1 and M2 segments in 6 cases, talamostriate arteries from PCoA and PCA in 4 patients, $\mathrm{AChA}$ in 3 cases and posterior choroidal arteries in 2 cases.

Five patients had deep venous drainage and 2 had only superficial venous drainage.

Five patients underwent transsylvian approach and 2 had transcortical approach. In 5 patients we achieved complete resection, postoperative angiography showed no residual nidus. In two cases, due to particular anatomy of the lesion, with passing arteries through the nidus which supply normal brain, that could not be proper identified during surgery, we 
could not perform complete resection. These 2 patients with residual nidus were referred to stereotactic radiosurgery Gamma Knife. Angiography done 18 months following radiation showed complete obliteration of the residual nidus in both cases.

Following surgery mRS improved in all 7 patients. Three patients present no significant disability ( $\mathrm{mRS} 1), 3$ had moderate disability (mRS 3 ) and one had moderately severe disability (mRS 4). Outcome was favorable in 3 cases and slowly favorable in 4 patients. Three patients presented no residual neurological deficits following surgery, 4 had residual paresis and 2 dysphasia. The patient with nonresponsive seizures, improved her mild brachial motor deficit, and was seizure-free at 3 years follow-up, under progressively reduced antiepileptic drugs (carbamazepine $600 \mathrm{mg} / \mathrm{d}$ ).

\section{Case 1}

A 27 years old woman was admitted in our department with altered mental state (GCS 9 points) and right hemiparesis with sudden onset. Cerebral CT scan showed a deep intraparenchymal hemorrhage, located in the left basal nuclei and thalamus. Four vessels angiography showed a deep seated, high-flow, SpetzlerMartin grade IV left basal ganglia and thalamic AVM, with multiple feeders from lenticulostriate arteries from M1, branches form M2, 3 thalamoperforating arteries from $\mathrm{P} 1$ and posterior choroidal artery and deep venous drainage into internal cerebral vein, through 3 tortuous enlarged veins.
The nidus measured $5 \mathrm{~cm}$ in length. The left ACA was injected only from the right ICA, showing vascular steal due to the AVM.

The patient underwent surgery, under general anesthesia. We performed a left frontotemporal craniotomy. We performed a transcortical approach through the posterior third of the inferior frontal lobe and one $\mathrm{cm}$ subcortically the hematoma is entered. The hematoma was evacuated and the nidus was identified. A circumferential dissection using the bipolar tangential to the wall of the AVM was performed, progressively closing feeding arteries. A major feeding artery, a branch from the posterior choroidal artery was identified and clipped. After this maneuver the nidus and draining veins into the internal cerebral vein collapsed, two of them being coagulated and dissected and the largest one clipped. The nidus was resected with less than $500 \mathrm{ml}$ blood loss. Yet, when the blood pressure was raised to control the hemostasis the walls of the resection cavity started to bleed heavily from a remnant of AVM that was coagulated and two main supplying arteries from MCA were identified and clipped. The operation was finalized with decompressive craniectomy, epidural silicone draining tube and wound closure in anatomical layers.

Postoperative the patient showed no new neurological deficits and during the first week her aphasia and hemiparesis improved. The control angiography showed no residual nidus and normal filling in the vascular territory of left MCA 
and PCA, also the left ACA was injected from the left ICA, because vascular steal disappeared ones the AVM was removed and normal blood flow was restored.

At 2 months follow-up she regained motor function and presented no aphasia. Cranioplasty was performed 4 months after initial operation.

\section{Case 2}

A 35 years old woman was transferred from another city with altered mental state, comatose state (GCS 6 points), right hemiplegia, intubated and ventilated, with left side oriented flexion to nociception.

Initial CT scan showed a massive deep left temporal intraparenchymatal hematoma.

The angiography showed a deep insular medium-flow grade III Spetzler-Martin AVM, with a nidus sizing $1.5 \mathrm{~cm}$ in diameter. The nidus was supplied by 4 feeders from MCA and had deep venous drainage through an enlarged sinuous vein into internal cerebral vein.

The patient underwent surgery. We performed a pterional craniotomy. The hematoma was approached through the sylvian fissure and the hematoma was entered $5 \mathrm{~mm}$ subcortical. When the hematoma was evacuated a $1.5 \mathrm{~cm}$ nidus appeared. Using circumferential dissection, the arterial feeders, branches from M1 and M2 were coagulated and sectioned. Than, after using the bipolar to shrink the nidus, the draining vein was identified coagulated and sectioned.
The nidus was completely removed. Following attentive hemostasis, the dura was closed, and bone flap was removed as a decompressive measure, we put an epidural silicone draining tube and wound was closed in anatomical layers.

Postoperative outcome was slowly favorable. Initially, she remained intubated and after three days she needed tracheostomy. Two weeks following surgery she regained consciousness, opened her eyes spontaneously, and obeyed commands.

Control angiography performed 1 month after surgery showed no residual nidus and normal vascularization in the MCA territory.

At 2 months follow-up she presented right hemiparesis.

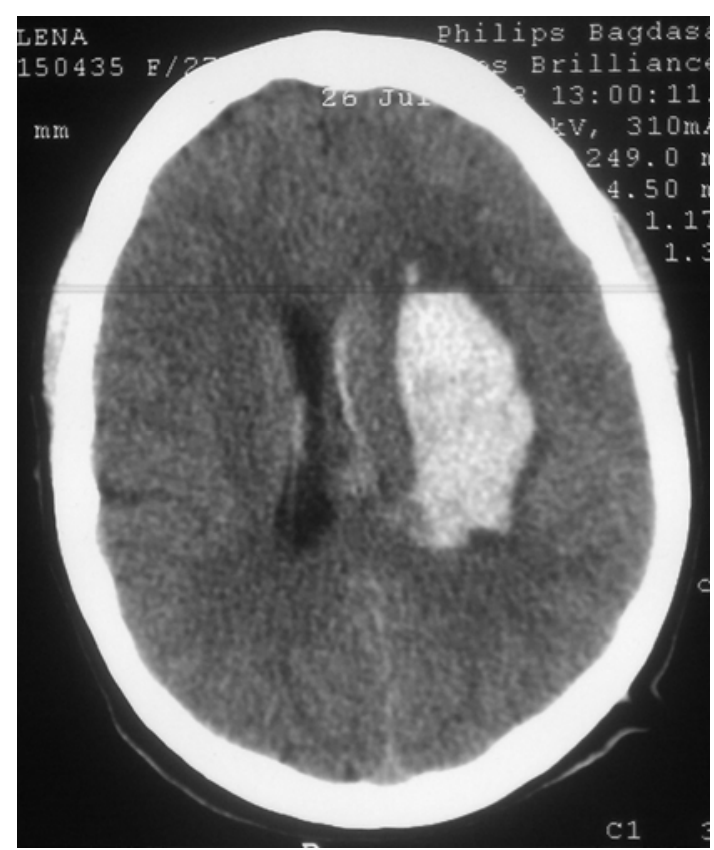



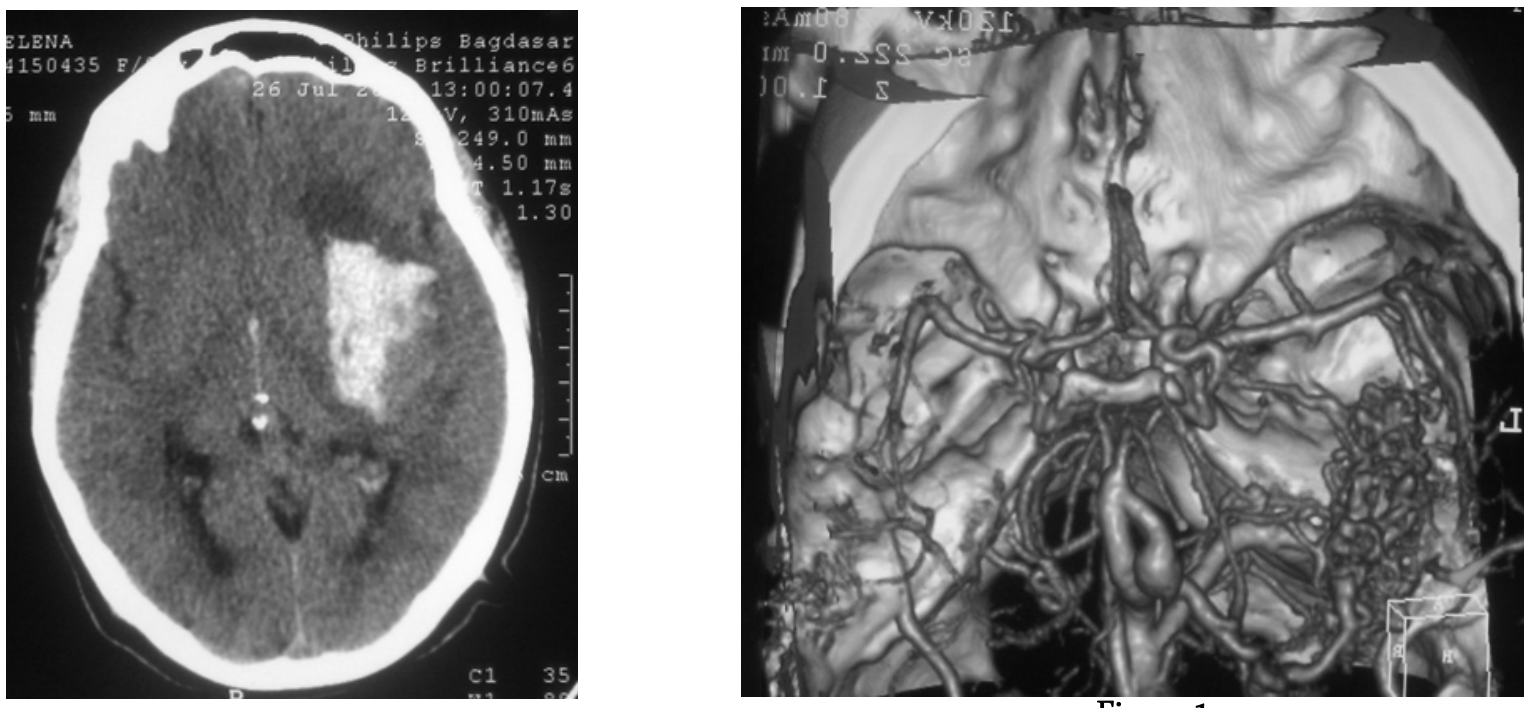

Figure 1

Preoperative CT \& angio-CT; massive left basal ganglia and thalamic intraparenchymatal hematoma caused by an ruptured AVM
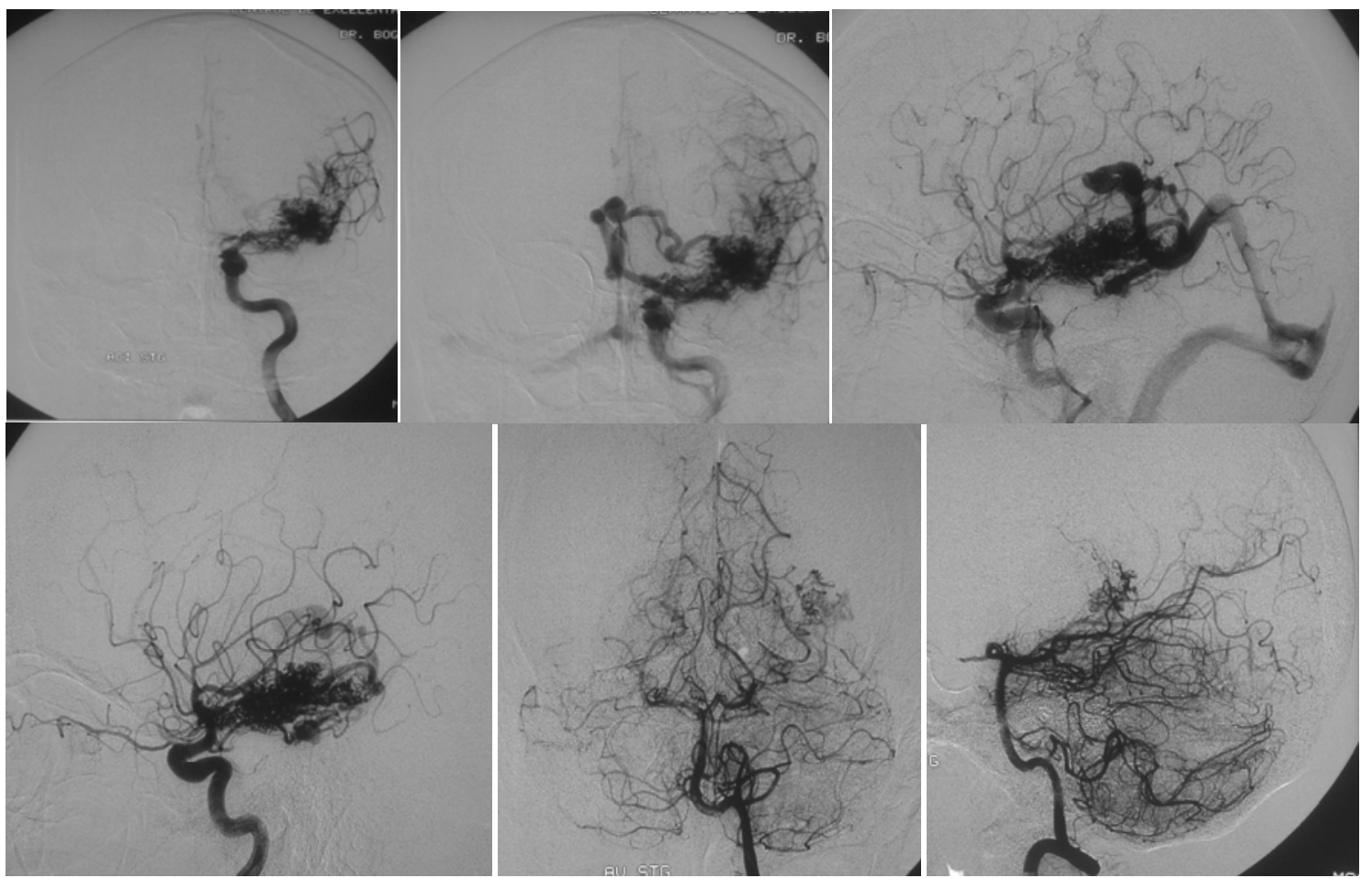

Figure 2

Preoperative angiography; high-flow AVM with multiple feeders from perforators of M1 and branches form M2 segments of the left MCA, thalamoperforating arteries from P1 segment of left PCA and left posterior choroidal artery; deep venous drainage into internal cerebral vein through 3 tortuous enlarged veins; nidus size $5 \mathrm{~cm}$ in length; vascular steal, left ACA was injected only from the right ICA 

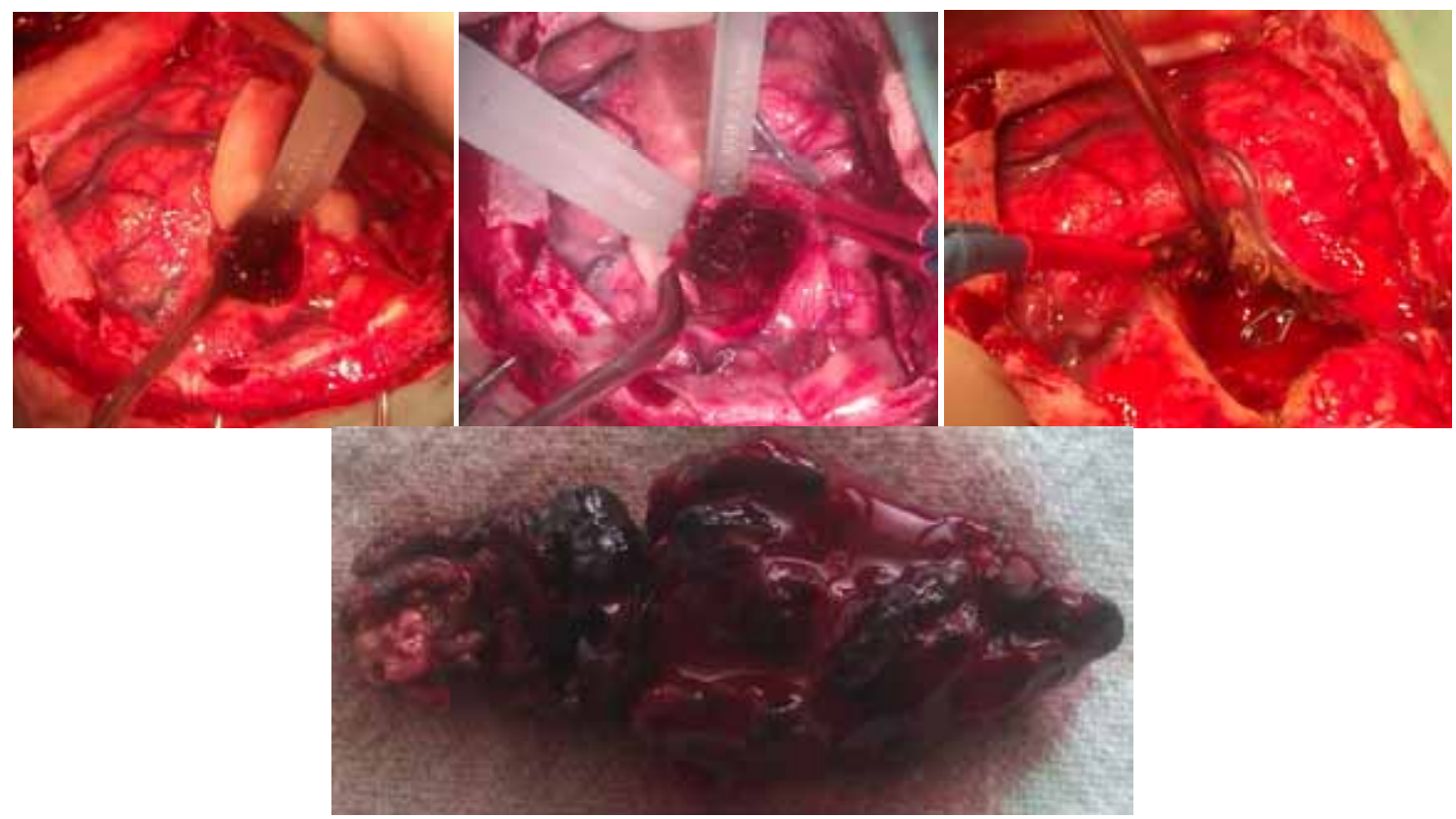

Figure 3

Intraoperatory images showing the nidus, the nidus after resection and the two clips on the feeders from MCA

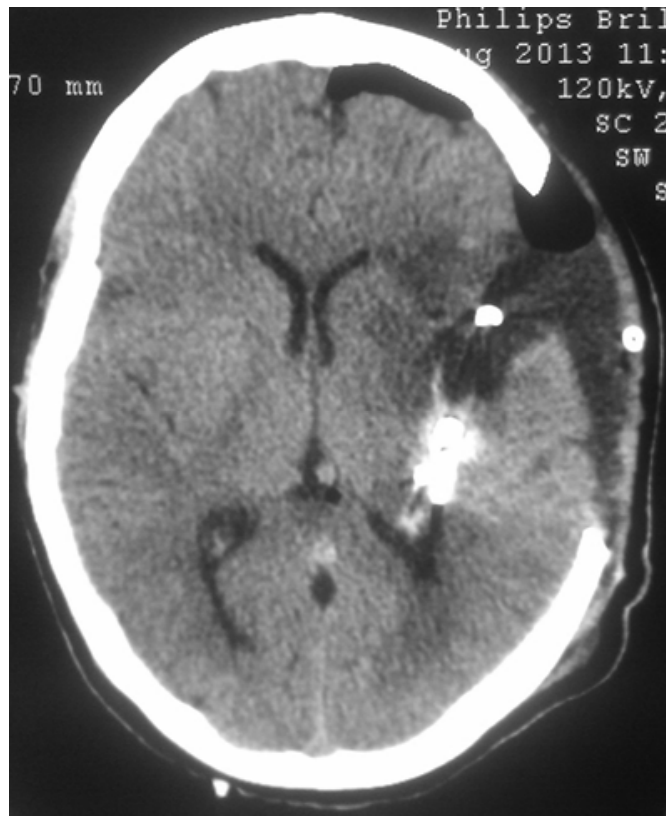

Figure 4

Postoperative CT; decompressive craniectomy, resection site and trajectory and vascular clips

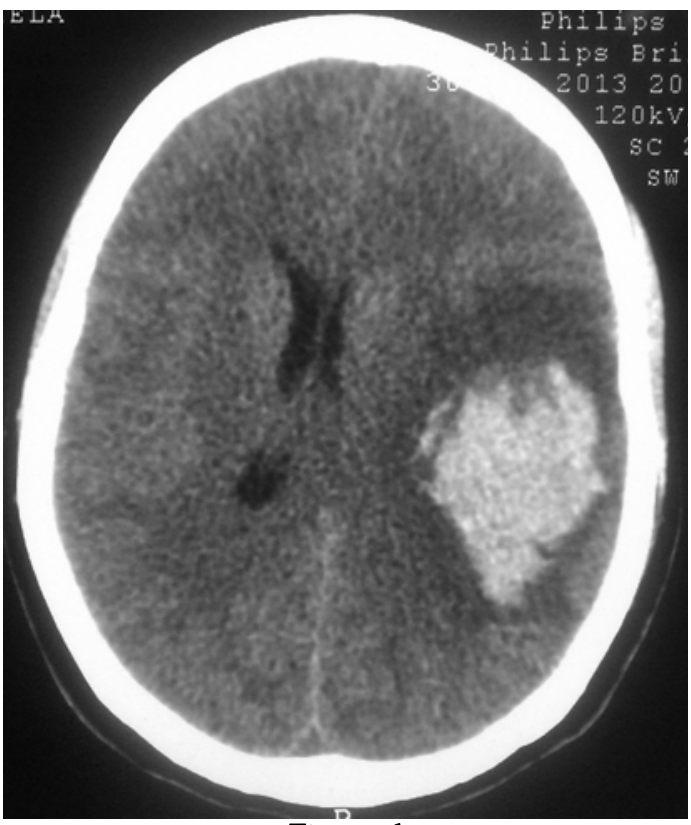

Figure 6

Preoperative CT; deep left temporal intraparenchymal hematoma 
DOI: 10.2478/romneu-2014-0001
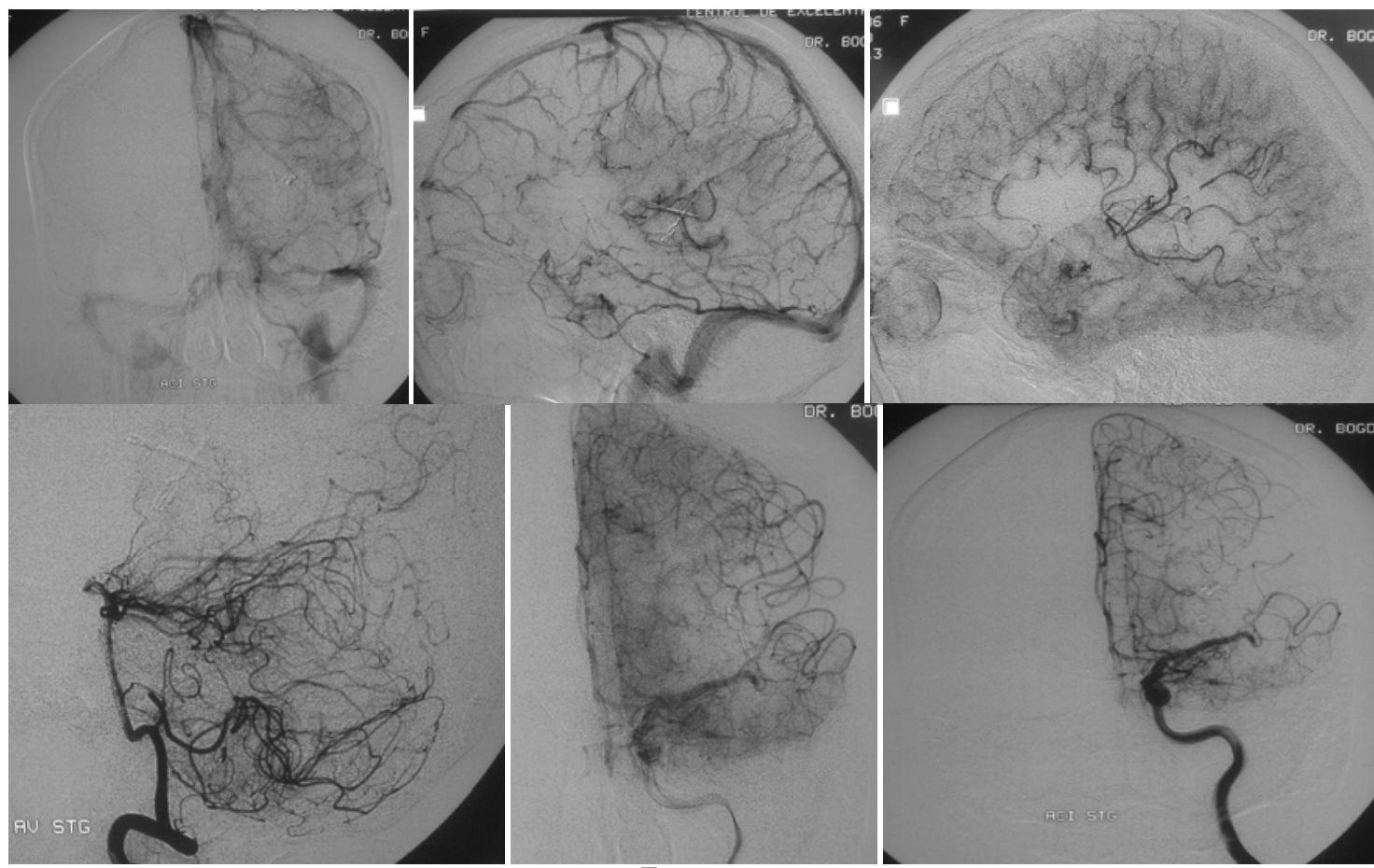

Figure 5

Postoperative angiography; no residual nidus and normal filling in the vascular territory of left MCA and PCA; no vascular steal
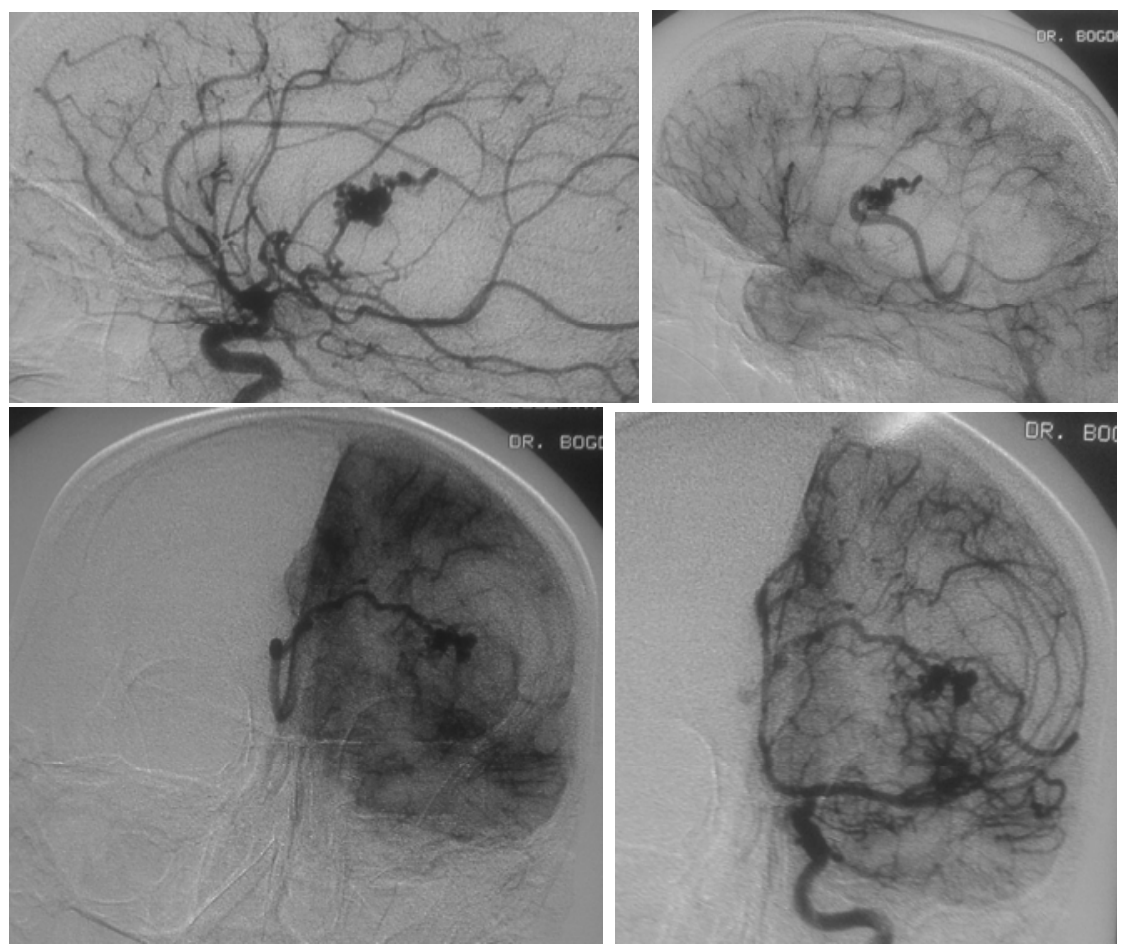

Figure 7

Preoperative angiography; arterial feeders from MCA and the deep venous drainage 


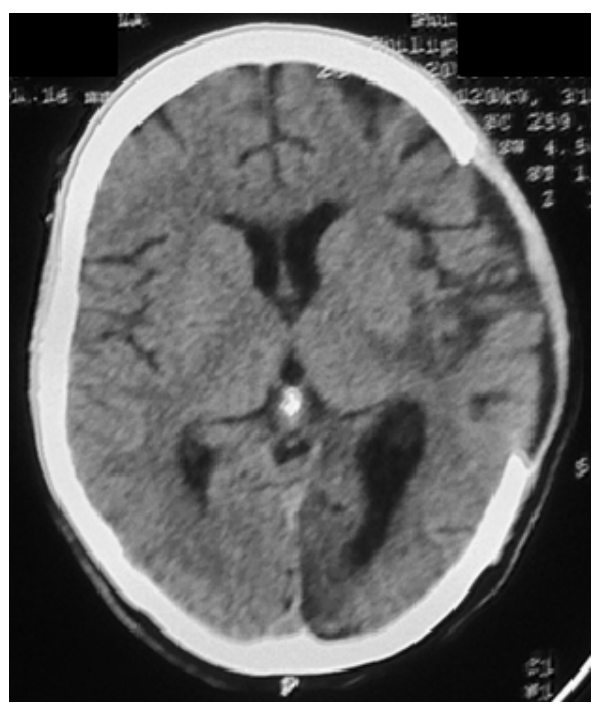

Figure 8

Postoperative CT; decompressive craniectomy, normal postoperative aspect

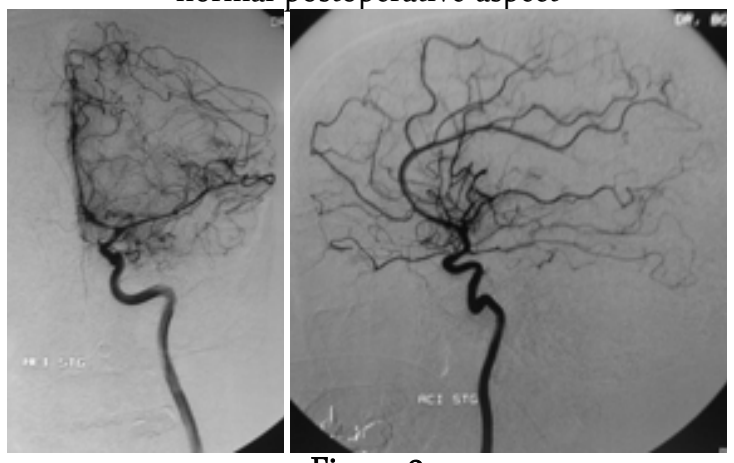

Figure 9

Postoperative angiography; no residual nidus and normal vascularization in the left MCA territory

\section{Discussions}

Over the time, many, different classifications of deep AVMs were used.

Oliveira et al. divided deep AVMs based on their vascular anatomy into: lateral AVMs, supplied mainly form lenticulostriate arteries, and MCA branches and occasionally from anterior choroidal artery and with both superficial and deep venous drainage; anteromedial
AVMs supplied by medial lenticulostriate arteries coming from M1 and A1 segments and with deep venous drainage into internal cerebral vein; thalamocaudate AVMs, supplied by either posterior choroidal and/or posterior pericallosal arteries or anterior pericallosal artery and AChA and most of them draining in the internal cerebral vein and a few in the superior sagittal sinus. (3)

In 2013, Lawton et al. came with a new, different classification based on the vascular anatomy of these lesions, considering insular, basal ganglia and thalamic AVMs. (23)

Insular AVMs are supplied by large branches coming from M2 segment or small perforators from the M1segment of MCA and venous drainage can be either deep into thalamostriate vein and Rosenthal basal vein or superficial into sylvian veins. $(23 ; 24)$

Basal ganglia AVMs are supplied by lenticulostriate arteries arising from M1 segment of MCA, branches from M2 and $\mathrm{AChA}$ and, in $80 \%$ of the cases, have deep venous drainage into internal cerebral vein or basal vein, or superficial venous drainage in $20 \%$ of patients into lateral subependymal or sylvian veins. $(23 ; 24)$

Thalamic AVMs are supplied from thalamoperforating arteries from P1 segment of PCA and PCoA, posterior lateral choroidal artery, posterior medial choroidal artery and AChA and deep venous drainage into internal cerebral or basal veins. $(23 ; 24)$ 
Sugita et al. classified sylvian fissure AVMs into lateral, medial and deep seated. (18)

Patients presented in our study were young women. Literature review shows that mean age for diagnosis of AVM is 33 years old and there is no gender preference. (7)

The most common onset in our series of was hemorrhage. Other authors made the same observation that deep AVMs are more prone to bleed compare with other locations, and found a bleeding rate of 9.8$34.4 \% /$ year $(4 ; 29)$. Onset is sudden, with altered mental state and new onset motor deficits. Close vicinity with internal capsule lead to motor deficits in all cases.

Seizures are uncommon in deep brain lesions, but the patient with secondary epilepsy had a ruptured AVM at age 14, with massive porencephalic cyst. Seizures were the consequence of cyst presence and their onset coincided with the rupture of the lesion.

As described in the literature (23) we also found deep venous drainage in the majority of the patients.

Surgery of deep AVMs is a continuous challenge due to deep and eloquent location, neighborhood with important critical brain structures, narrow and deep surgical corridor, limited operative field and tangential dissection. $(8 ; 10 ; 17 ; 22 ; 23$; 30)

Several approaches for deep AVMs had been descried: transsylvian (anterior transinsular anterior, posterior transinsular, supracarotid infrafrontal), transcallosal (anterior ipsilateral, anterior contralateral, transchoroidal, posterior) Și transcortical (frontal, temporal, parietal). $(16 ; 22 ; 23 ; 28 ; 31)$ All of these approaches present its advantages and drawbacks and offers access to different areas of deep seated structures. Choosing the optimal approach is very important and must be individualized for each patient and depends on: AVM location, neurological status and surgeon experience.

Transsylvian approach implies meticulous splitting of sylvian fissure, respecting pial planes, overlying middle cerebral veins, branches of the MCA and lenticulostriate and insular perforating arteries. (22) Surgical corridor in transsylvian-transinsular approaches places insular segments of MCA between the surgeon and the AVM. (22) Transcallosal approaches do not pass through the brain in order to access the lesion, and the risk for postoperative seizures occurrence is minimal. (16; 28) Transcortical approaches are used in ruptured AVMs with secondary intraparechymatal hematoma. $(15 ; 23)$

In unruptured AVMs surgical approach should be tailored as to access the AVM with minimal damage of normal brain, while creating a working corridor, that allows access first to the arterial supply and finally to the draining veins. In ruptured AVMs the working corridor is already made by the hematoma, the access should be through a transsylvian or transcortical route into the hematoma, after the emptying of which the AVM comes into view. Ruptured AVMs are easier to 
operated compared to unruptured lesions and the rate of total resection in higher in the first category. (8)

In our series of patients we preferred transsylvian approach in the majority of cases.

Following surgery and hematoma evacuation all motor deficits improved, but patients presented with severe paralysis presented residual neurological deficits.

There are some surgical challenges for deep AVMs. Most of these deep AVMs are supplied from small perforators, which are very difficult to coagulate without damaging the normal parenchyma.

In many situations total nidus resection cannot be achieved, the rate of subtotal resection being higher compared with other locations. $(5 ; 12 ; 23 ; 25)$ Incomplete resection is due to proximity of critical structures, such as internal capsule or thalamus or presence of passing arteries (26). Passing arteries must be preserved, because they feed normal brain, and their unfortunate scarification lead to ischemic stroke and new neurological deficits.

The poor natural history of deep AVMs makes them more aggressive than other supratentorial AVMs and thus treatment can include preoperative embolization or radiosurgery, used as a main treatment or as an adjuvant, to treat remnants of AVM after the surgery.

Like other authors that reported good results following deep AVMs (14; 23), we also believe that good outcome can be achieved in deep AVMs. Surgery is the treatment of choice in ruptured AVMs (6), because it allows hematoma evacuation and permits cure of the lesion, allowing motor deficit improvement and eliminating the risk of bleeding.

In acute setting of a ruptured AVM, surgical treatment is the only chance for the patient's survival, if a surgeon experienced in this kind of lesions is available as soon as possible.

\section{Conclusions}

Deep AVMs frequently present sudden onset, aggressive and dramatic outcome, altered mental state and large intraparenchymatal hematomas and require emergent surgery, in the majority of cases preoperative embolization being unavailable. Most patients present motor deficits due to close proximity with internal capsule. Surgery is mandatory for deep ruptured AVMs. Surgery is the only treatment that can provide neurological improvement through hematoma evacuation and cure through nidus resection. Surgery can be performed using transsylvian or transcortical approach, depending on nidus and hemorrhage characteristics. In experience hands, deep AVMs can be successfully resected. Patients with residual nidus can benefit from stereotactic radiosurgery Gamma Knife with good outcome. Postoperative results are good, with improvement of state of consciousness and motor deficits. Adequate patient selection is essential in order to achieve a good postoperative outcome. 


\section{Correspondence to:}

Aurelia Mihaela Sandu

Address: Fourth Department of Neurosurgery,

Emergency Clinical Hospital Bagdasar-Arseni,

No. 10-12, Berceni Street, Sector 4, Bucharest; e-

mail: aurasandu@gmail.com; tel.0724.263.023

\author{
Abreviations \\ $A C A$ - anterior cerebral artery \\ AChA - anterior choroidal artery \\ AVM - arteriovenous malformation \\ $C T$ - computer tomography \\ GCS - Glasglow Coma Scale \\ grade SM - grade Spetzler-Martin \\ ICA - internal cerebral artery \\ $M C A$ - middle cerebral artery \\ $M R I$ - magnetic resonance imaging \\ $m R S$ - modified Rankin scale \\ $P C A$ - posterior cerebral artery \\ $P C o A$ - posterior communicating artery
}

\section{References}

1. Andrade-Souza YM, Zadeh G, Scora D, Tsao MN, Schwartz ML. (2005). Radiosurgery for basal ganglia, internal capsule, and thalamus arteriovenous malformation: clinical outcome. Neurosurgery. 56, 5663.

2. Cheng CH, Crowley RW, Yen CP, Schlesinger D, Shaffrey ME, Sheehan JP. (2012). Gamma Knife surgery for basal ganglia and thalamic arteriovenous malformations. J Neurosurg. 116, 899-908.

3. de Oliveira E, Tedeschi H, Siqueira MG, Ono M, Rhoton AL Jr, Peace D. (1994). Anatomic principles of cerebrovascular surgery for arteriovenous malformations. Clin Neurosurg. 41, 364-380.

4. Fleetwood IG, Marcellus ML, Levy RP, Marks MP, Steinberg GK. (2003). Deep arteriovenous malformations of the basal ganglia and thalamus: natural history. J Neurosurg. 98, 747-750.

5. Gabarros Canals A, Rodriguez-Hernandez A, Young WL, Lawton MT, for the UCSF Brain AVM Study Project. (2013) Temporal lobe arteriovenous malformations: anatomical subtypes, surgical strategy, and outcomes. J Neurosurg. Epub ahead of print [DOI: 10.3171/2013.6.JNS122333].

6. Gorgan RM. (2011). Malformațiile arteriovenoase cerebrale, in Ciurea AV (ed): Tratat de neurochirurgie. Bucureşti, Editura Medicală, pp 117-129.

7. Greenberg MS. (2010). Vascular malformations, in Greenberg MS (ed): Handbook of neurosurgery. New York, Thieme Medical Publisher, pp 1098-1142.

8. Gross BA, Duckworth EA, Getch CC, Bendok BR, Batjer HH. (2008). Challenging traditional beliefs: microsurgery for arteriovenous malformations of the basal ganglia and thalamus. Neurosurgery. 63, 393-410.

9. Hashimoto N, Nozaki K, Tagaki Y, Kikuta K, Mikuni N. (2007). Surgery of cerebral arteriovenous malformations. Neurosurgery. 61 (SHC Suppl 1), SHC 375-SHC 389.

10. Johnston JL, Johnston IH. (1996). The surgical treatment of small deep intracranial ateriovenous malformations: a report of 85 cases. J Clin Neurosci. 3, 338-345.

11. Kano H, Kondziolka D, Flickinger JC, Yang HC, Flannery TJ, Niranjan A, Novotny J Jr, Lunsford LD. (2012). Stereotactic radiosurgery for arteriovenous malformations, Part 4: management of basal ganglia and thalamus arteriovenous malformations. J Neurosurg. 116, 33-43.

12. Kim YB, Young WL, Lawton MT, for the UCSF Brain AVM Study Project. (2011). Parafalcine and midline arteriovenous malformations: surgical strategy, techniques, and outcomes. J Neurosurg. 114, 984-993.

13. Kiran NAS, Kale SS, Kasliwal MK, Vaishya S, Gupta A, Singh Sharma M, Shankar Sharma B, Kumar Mahapatra A. (2009). Gamma knife radiosurgery for arteriovenous malformations of basal ganglia, thalamus and brainstem--a retrospective study comparing the results with that for AVMs at other intracranial locations. Acta Neurochir (Wien). 151, 1575-1582.

14. Lawton MT. (2003). Spetzler-Martin Grade III arteriovenous malformations: surgical results and a modification of the grading scale. Neurosurgery. 52, 740-748.

15. Lawton MT, Du R, Tran MN, Achrol AS, McCulloch CE, Johnston SC, Quinnine NJ, Young WL. (2005). Effect of presenting hemorrhage on outcome after microsurgical resection of brain arteriovenous malformations. Neurosurgery. 56, 485-493.

16. Lawton MT, Golfinos JG, Spetzler RF. (1996). The contralateral transcallosal approach: experience with 32 patients. Neurosurgery. 39, 729-734.

17. Lawton MT, Hamilton MG, Spetzler RF. (1995). Multimodality treatment of deep arteriovenous malformations: thalamus, basal ganglia, and brain stem. Neurosurgery. 37, 29-35. 
18. Lawton MT, Lu DC, Young WL, for the UCSF Brain AVM Study Project. (2007). Sylvian fissure arteriovenous malformations: an application of the Sugita classification to 28 surgical patients. Neurosurgery. 61, 29-36.

19. Liscak R, Vladyka V, Simonova G, Urgosik D, Novotny J Jr, Janouskova L, Vymazal J. (2007). Arteriovenous malformations after Leksell gamma knife radiosurgery: rate of obliteration and complications. Neurosurgery. 60, 1005-1014.

20. Nagy G, Major O, Rowe JG, Radatz MW, Hodgson TJ, Coley SC, Kemeny AA. (2012). Stereotactic radiosurgery for arteriovenous malformations located in deep critical regions. Neurosurgery. 70, 1458-1469.

21. Nicolato A, Foroni R, Crocco A, Zampieri PG, Alessandrini F, Bricolo A, Gerosa MA. (2002). Gamma knife radiosurgery in the management of arteriovenous malformations of the basal ganglia region of the brain. Minim Invasive Neurosurg. 45, 211-223.

22. Potts MB, Chang EF, Young WL, Lawton MT, for the UCSF Brain AVM Study Project. (2012). Transsylvian-transinsular approaches to the insula and basal ganglia: operative techniques and results with vascular lesions. Neurosurgery. 70, 824-834.

23. Potts MB, Young WL, Lawton MT, for the UCSF Brain AVM Study Project. (2013). Deep arteriovenous malformations in the basal ganglia, thalamus, and insula: microsurgical management, techniques, and results. Neurosurgery. 73, 417-427.

24. Rhoton AL Jr. (2002). The supratentorial cranial space: microsurgical anatomy and surgical approaches.
Neurosurgery. 51 (Suppl 14 ), S1-1-S1-410.

25. Rodriguez-Hernandez A, Kim H, Pourmohamad T, Young WL, Lawton MT. (2012). Cerebellar arteriovenous malformations: anatomic subtypes, surgical results, and increased predictive accuracy of the supplementary grading system. Neurosurgery. 71, 11111124 .

26. Sandu AM, Gorgan MR. (2011). Multimodal treatment for temporobasal arteriovenous malformation - case report. Ro Neurosurg. 18, 499-510.

27. Sasaki T, Kurita H, Saito I, Kawamoto S, Nemoto S, Terahara A, Kirino T, Takakura K. (1998). Arteriovenous malformations in the basal ganglia and thalamus: management and results in 101 cases. J Neurosurg. 88, 285-292.

28. Shucart WA, Stein BM. (1978). Transcallosal approach to the anterior ventricular system. Neurosurgery. 3, 339-343.

29. Stapf C, Mast H, Sciacca RR, Choi JH, Khaw AV, Connolly ES, Pile-Spellman J, Mohr JP. (2006). Predictors of hemorrhage in patients with untreated brain arteriovenous malformation. Neurology. 66, 13501355.

30. U HS, Kerber CW, Todd MM. (1992). Multimodality treatment of deep periventricular cerebral arteriovenous malformations. Surg Neurol. 38, 192-203. 31. Waldron JS, Lawton MT. (2009). The supracarotidinfrafrontal approach: surgical technique and clinical application to cavernous malformations in the anteroinferior basal ganglia. Neurosurgery. 64[3 suppl], ONS 86-ONS 95. 